First submitted to Civil Engineering 11 May 2016

\title{
Title: Strategic analysis of the future of national infrastructure
}

Prof Jim W Hall BEng, MA, PhD, CEng, FREng, FICE

Environmental Change Institute, University of Oxford, UK

Dr Scott Thacker, MEng, DPhil

Environmental Change Institute, University of Oxford, UK

Dr Matt Ives, BSc, MSc, PhD

Environmental Change Institute, University of Oxford, UK

Yue Cao, BSc, MSc

Environmental Change Institute, University of Oxford, UK

Dr Modassar Chaudry, BSc, MSc, PhD

Institute of Energy, Cardiff University, UK

Dr Edward Oughton, BSc, MPhil, PhD

Centre for Risk Studies, University of Cambridge, UK

Corresponding author:

Prof Jim Hall

Environmental Change Institute

Oxford University Centre for the Environment,

South Parks Road,

Oxford,

OX1 3QY, UK

Email: jim.hall@eci.ox.ac.uk

Phone: +44 (0)1865 275846 (Direct); +44 (0)1865 275847 (Sue King PA)

Number of words in main text: 4027

Number of figures: 8 


\begin{abstract}
There have been many calls for a more strategic, long-term approach to national infrastructure in the UK and elsewhere around the world. Whilst appealing in principle, in practice developing a national infrastructure strategy brings major challenges of complexity and uncertainty. The UK Infrastructure Transitions Research Consortium (ITRC) has set out a systematic methodology for long term analysis of the performance of national infrastructure systems, which deals with each infrastructure sector (energy, transport, digital communications, water supply, waste water, flood protection and solid waste) in a consistent framework and calculates the implications of interdependencies between infrastructure sectors. The methodology is supported with the world's first infrastructure system of systems model (NISMOD), which has been developed for long term decision analysis in interdependent infrastructure systems. NISMOD has been applied to analyse the national infrastructure strategy that has been developed in the National Needs Assessment led by ICE President Sir John Armitt.
\end{abstract}

\title{
Keywords
}

Infrastructure planning, Economics and finance, Mathematical modelling, Sustainability

\section{The challenges for national infrastructure in the UK and globally}

National infrastructure systems form the basis for a society's economic and human wellbeing and environmental sustainability. These systems, which include energy, transport, digital communications, water supply, waste water, flood protection and solid waste, require very significant capital investments that have long lead-times and life-times. Building infrastructure is a long-term commitment that is very difficult to reverse, which means that infrastructure decisions have major implications for sustainability, notable mitigation of carbon emissions and adaptation to the impacts of climate change.

Governments in advanced economies worldwide have to cope with an ageing stock of infrastructure that needs to meet growing demands for infrastructure services. Meanwhile major infrastructure investments are taking place in emerging economies which will lock in patterns of development for decades to come. Least developed countries struggle with the greatest deficit in infrastructure provision, including basic energy, water and sanitation services and transport connectivity that would enable trade and growth. Overall, Standard \& Poor's (S\&P) and McKinsey estimate that \$57 trillion, or $\$ 3.2$ trillion a year, will be needed to finance infrastructure development around the world over the next 15 years.

Infrastructure is the second pillar of the World Economic Forum's Global Competitiveness Report. Britain was ranked $10^{\text {th }}$ in that league table in 2014/15, behind France (8th), Germany (7th), but ahead of the USA (12th). The American Society of Civil Engineers' 2013 Report Card for America's Infrastructure estimated that $\$ 3.6$ trillion is needed for America's infrastructure by 2020 . The ICE's State of the Nation Infrastructure assessment in 2014 gave Britain's infrastructure the following grades: energy C-, strategic transport B, local transport D-, flood management C-, water B and waste $\mathrm{C}+$. The report cited evidence of lack of resilience to extreme events and weak commitment in the transition to low carbon infrastructure networks.

In recognition of these challenges, the UK has been developing a more systematic approach to national infrastructure. Infrastructure UK was created within HM Treasury in 2010, publishing annual 
National Infrastructure Plans between 2011 and 2014. In 2013 Sir John Armitt led an independent review of long term infrastructure planning, recommending the creation of a National Infrastructure Commission, a proposal that was strongly supported by the ICE. The creation of the National Infrastructure Commission (NIC) was announced by the Chancellor in 2015. The NIC is chaired by Lord Adonis and charged with carrying out a National Infrastructure Assessment (NIA) by the end of the current parliament. To pave the way for the NIA, Sir John Armitt has launched a National Needs Assessment (NNA), which is developing an in-depth analysis of the future needs for infrastructure services and an independent vision for what the UK's infrastructure systems should look like decades in the future.

\section{National infrastructure assessment}

Whilst there are well established investment planning methodologies in some infrastructure sectors, conducting cross-sectoral national NIA raises challenges that have only very recently been addressed by new methodology and 'system of systems' simulation models (Hall et al., 2016). The two most difficult challenges for NIA are (i) complexity and (ii) uncertainty. Complexity arises from the number of 'moving parts' in the national infrastructure system of systems, and the interdependency between different sectors. Dealing with complexity requires a rigorous conceptual framework and a common set of assumptions which can be applied across infrastructure sectors.

Uncertainty means that any deterministic masterplan for infrastructure investment would be vulnerable to unexpected future changes. Many of the factors that determine the future demand for infrastructure services, including population, economic growth and technology, are highly uncertain. An assessment framework should therefore be based around the development of adaptable strategy, whilst at the same time providing a clear sense of direction and confidence that long term targets, for example for carbon emissions, can be met.

The framework for NIA that we have developed (Figure 1) uses scenarios to explore uncertainty in a range of possible futures: the global and national economy; population/demography at national and local scales; climate change; technological development. These scenarios explore the possible range of contextual factors that are largely outside the control of decision makers responsible for national infrastructure. Of course there are feedbacks between the infrastructure system and these factors, notable in terms of regional economic development: provision of infrastructure can stimulate the economy, provide new employment opportunities and hence change where people live. These feedbacks are important to recognise but much more difficult to quantify (Venables et al., 2014) attempting to model them would introduce additional complexity which for the time being we consider to be unwarranted. We prefer to explore the possible impacts of infrastructure investment on regional economies by using scenarios that test the possibility of additional growth being stimulated by infrastructure provision.

Alongside scenarios, our framework for NIA explores one or more infrastructure strategies. Strategies are sequences of infrastructure investments and policy/regulatory interventions that are intended to modify demand for, or provision of, infrastructure services. Strategies must be sufficiently adaptable to cope with uncertain scenarios, for example of population growth. On the other hand, a national infrastructure strategy must give a clear sense of direction about what policies and investments need to be implemented, where and when. These are the big political choices. In the end these choices largely boil down to political judgements in three areas: 
1. How much are we prepared to invest in infrastructure? For the time being, public and private investment in national infrastructure is $2.8 \%$ of GDP in the UK, compared to an OECD target of 3.5\% of GDP (House of Commons, 2015). The cost of these investments has to be recovered sooner or later, via a combination of user charging and taxation.

2. How prepared are we to commit to policies to manage demand for infrastructure, such as road user charging, compulsory smart metering or building regulation? Demand management strategies can improve the efficiency of infrastructure provision, often a relatively low financial cost, but they can come at a high political price and may suppress economic activity.

3. How do we wish to balance the different objectives for infrastructure? For a given level of investment there are many trade-offs to be made (and potential synergies to be sought) around the quality, reliability and resilience of infrastructure services for the economy and society, and the environmental impacts of infrastructure (for example in terms of carbon emissions, local air pollutants and water quality). Likewise, trade-offs have to be negotiated about the balance of provision between different regions and the legacy of infrastructure and/or debt to be left to future generations.

Setting the overall vision for national infrastructure involves political judgements on each of these dimensions. A high quality, low cost, environmentally friendly infrastructure system that doesn't involve unpalatable new regulation of demand unfortunately does not exist. Hard political choices have to be made. The NNA's vision for national infrastructure is that "The UK will invest efficiently, affordably and sustainably in the provision of infrastructure assets and services to drive the economic growth necessary to enhance the UK's position in the global economy, support a high quality of life and shift towards a low carbon future."

That overall vision implies the broad direction of strategies for each infrastructure sector, but a series of choices is needed to establish which combination of investments and policies can deliver the overall vision. It is at this stage that quantified analysis is most needed to demonstrate that the proposed interventions will deliver the requisite performance in given scenarios. To quote the late David McKay's book on sustainable energy (McKay, 2008) "Make sure your policies include a plan that adds up!" Analysis of system performance needs to take place at a range of future timescales (years and decades ahead) and on appropriate spatial and temporal scales e.g. distinguishing between 'peak' and 'off peak' demands in energy and transport to demonstrate the benefits of demand management and energy storage.

Analysis, supported by models, is also required to deal with cross-sectoral interdependencies. Though there are many interdependencies, from an infrastructure assessment and planning perspective the interdependencies that matter most are when (i) demand for one infrastructure sector is highly correlated with demand for another (e.g. domestic demand for water and energy) and/or (ii) when one infrastructure sector can potentially consume a significant proportion of the capacity of another, notably in power generation, which is responsible for $40 \%$ of non-tidal surface water abstractions (Byers et al., 2014), and in transport strategies that include largescale uptake of electric vehicles, which could eventually use more than $15 \%$ of electricity generation.

Comparison of alternative strategies, in the context of given scenarios, is done based on projected values of a small set of relevant metrics, which include: the amount of infrastructure service the 
system could deliver; the margin between system capacity and projected system use, which gives a metric of reliability; the capital and operation costs of the system and; metrics of environmental impact, including carbon emissions. These metrics provide the basis for choosing between alternative strategies. They will vary geographically and through time. They will also depend on the scenarios considered, so judgements will be required about the acceptable level of performance and the range of scenarios over which that performance is sought (Otto et al., 2014). National Infrastructure Assessment cannot answer these questions, but it provides the evidence about the possible performance of alternative strategies to enable informed decision making.

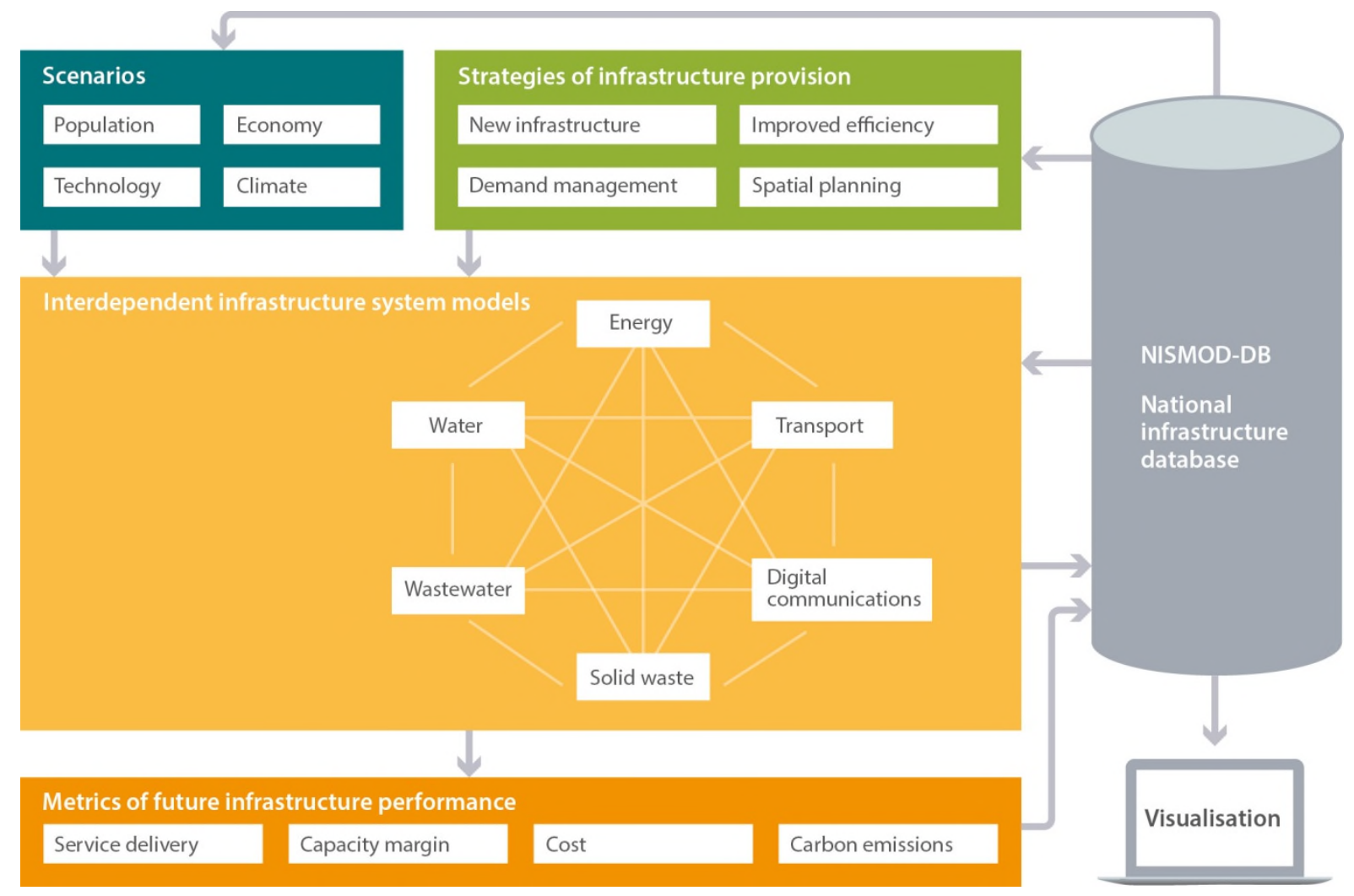

Figure 1 Schematic overview of the use of NISMOD for national infrastructure assessment

\section{NISMOD: National Infrastructure Systems Model}

Whilst there have been many calls for a strategic approach to infrastructure provision, for the time being a substantial, specific and forward looking cross-sectoral strategy has not yet been developed in any country worldwide. One reason for this lack of strategic analysis is the lack of methodology to develop long-term cross-sectoral strategies and the lack of models and tools to analyse infrastructure strategies. We believe that a national infrastructure assessment cannot be carried out without the benefit of some form of systems modelling to rigorously deal with the challenges of complexity and uncertainty.

The UK Infrastructure Transitions Research Consortium (ITRC) was launched in 2011 with the aim to develop and demonstrate a new generation of simulation models and methods to inform analysis, planning and design of national infrastructure systems. The ITRC was backed by $£ 4$.7million of funding from the Engineering and Physical Sciences Research Council (EPSRC) and has recently been awarded a further $f 5.3$ million to continue the research programme through to 2020 . 
During the first five years of research, the ITRC developed the National Infrastructure Systems Model (NISMOD), which was designed to provide the evidence to inform national infrastructure assessment. The structure of NISMOD is illustrated in Figure 1. Infrastructure and scenario data are held in a shared national infrastructure database, NISMOD-DB. That rigorous structure enables each combination of scenarios and strategies to be accessed and scrutinised. Visualisation facilities enable presentation of maps, time series and other graphics. Additionally optimisation routines enable combinations of interventions to be developed that meet specified objectives or are subject to given constraints.

\section{Populations and economic scenarios for Britain}

The population scenarios used in NISMOD are based on Office of National Statistics projections through the $21^{\text {st }}$ Century, downscaled using NISMOD to the resolution need for infrastructure assessment. Figure 2 illustrates the range of regional variations in populations that has been considered to stress test possible national infrastructure strategies. NISMOD's economic scenarios are based on Cambridge Econometrics' multi-sectoral model of the UK economy which generates projections of output and employment, thus helping to explore the range of possible economic demands for infrastructure services.

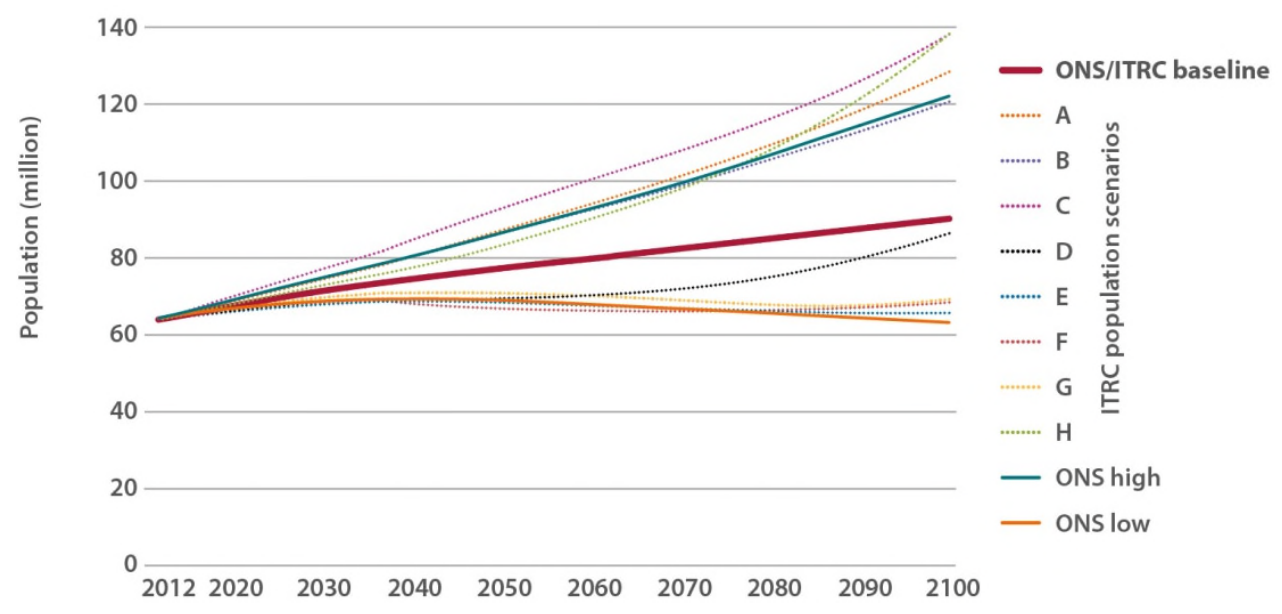

Figure 2 NISMOD scenarios of national population 

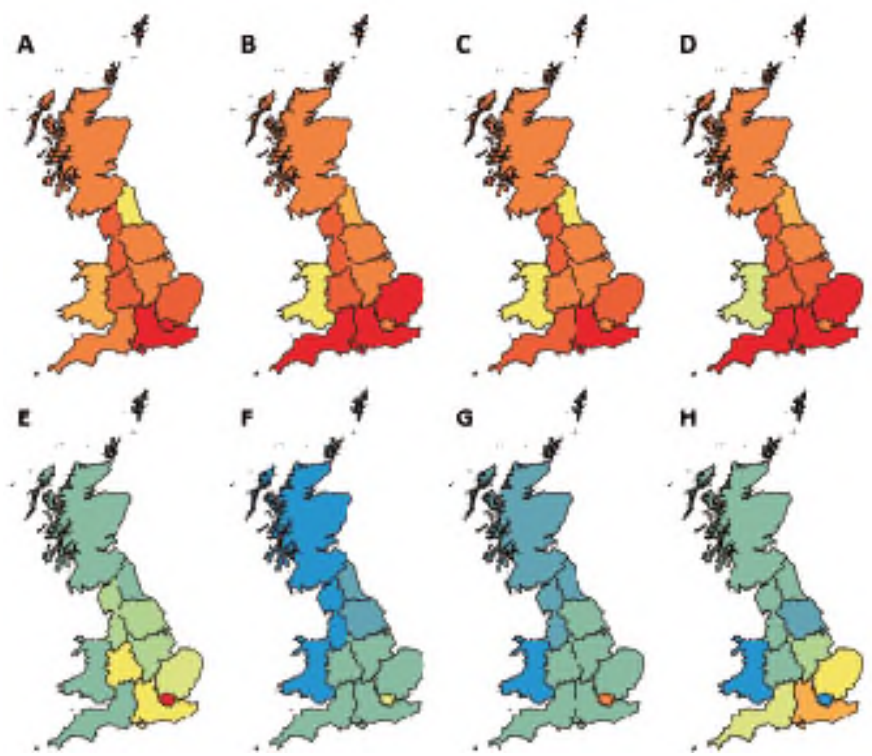

Change in population:

2012 to 2100

(thousands)

G

-1318 to -300

-299 to 0

1 to 700

701 to 1200

1201 to 1700

1701 to 2100

2101 tu 2800

2801 to 5600

5601 to 7500

7501 to 25341

Figure 3 NISMOD scenarios of regional population change

\section{Sector strategies in the National Needs Assessment}

NISMOD contains planning models for energy (electricity and gas), transport (road, rail, ports, airports), digital communications, water supply, flood defence, waste water and solid waste. Crosssectoral interdependencies in the long term planning version of NISMOD (NISMOD-LP) are focussed on demand for electricity and liquid fuels in the transport sector and demand for cooling water for thermos-electric generation plant. Each of these planning models contains a module for estimating the demand for infrastructure services, given the population and economic scenarios and policy and pricing choices that determine the demand elasticity in each infrastructure sector. Spatially resolved system models then simulate how those demands might be met for a given system configuration. This can involve iteration between demand and system simulation, as in the case of the road network, in which congestion feeds back to suppress demand, whilst provision of new road space can release latent demand.

The strategy for the energy sector in the NNA is based upon the UK meeting its carbon target of an $80 \%$ reduction in carbon emissions (relative to 1990 levels), which implies almost complete decarbonisation of the electricity system and extensive electrification of heat and land transport. Vigorous policies to reduce energy demand in buildings are cost-beneficial (Frontier Economics, 2015) so are prioritised in the NNA, though electrification of heat and transport, alongside projected population increases, will push up demand for electricity (Figure 4), so it is important that low carbon generation capacity is in place first. Distributed renewables (notably photo-voltaics) and distributed storage, both of which are rapidly falling in price, can help to mitigate peak demands upon the grid. 


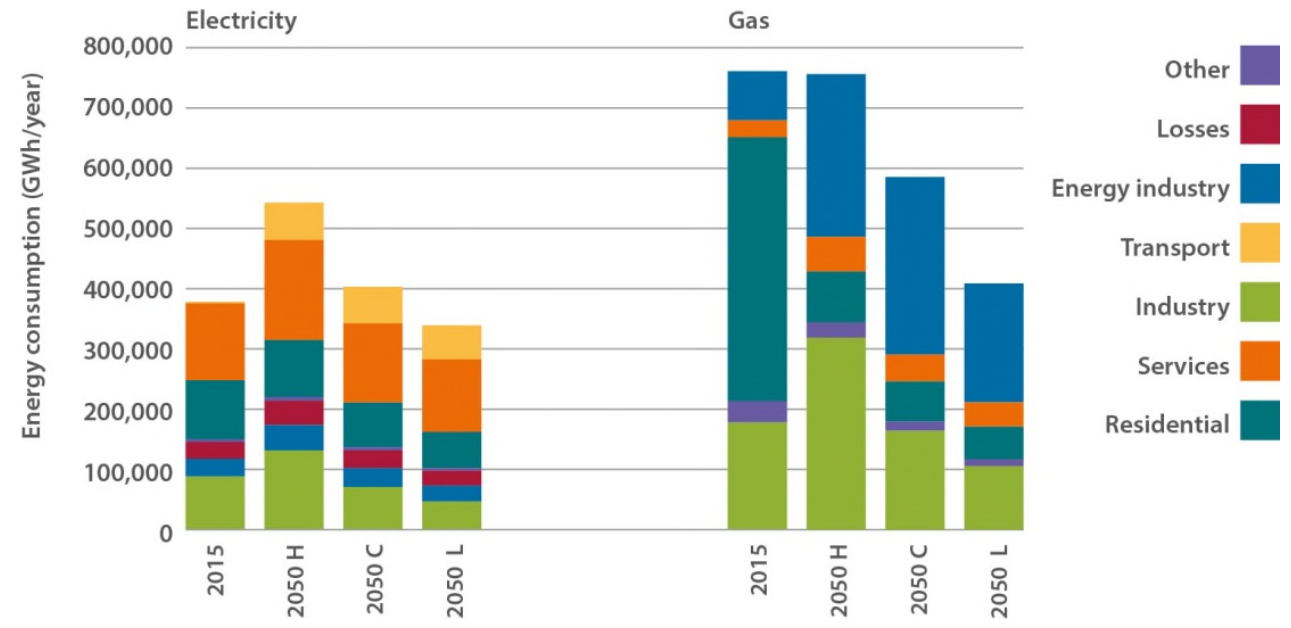

Figure 4 NISMOD projections of energy demand, for different population and economic growth scenarios

Figure 5 illustrates possible low carbon supply portfolios that will meet these demands. This implies rapid scaling up of offshore wind alongside a baseload component of nuclear supply. Gas turbines (CCGTs) fill the supply gap as a transitional fuel and provide backup for intermittent renewables. With North Sea gas reserves projected to run down and domestic shale gas unlikely to be extracted on a sufficient scale, additional LNG import and storage capacity will be required. To meet carbon targets, CCGTs will have to be fitted with carbon capture and storage, for which a UK system is urgently required.
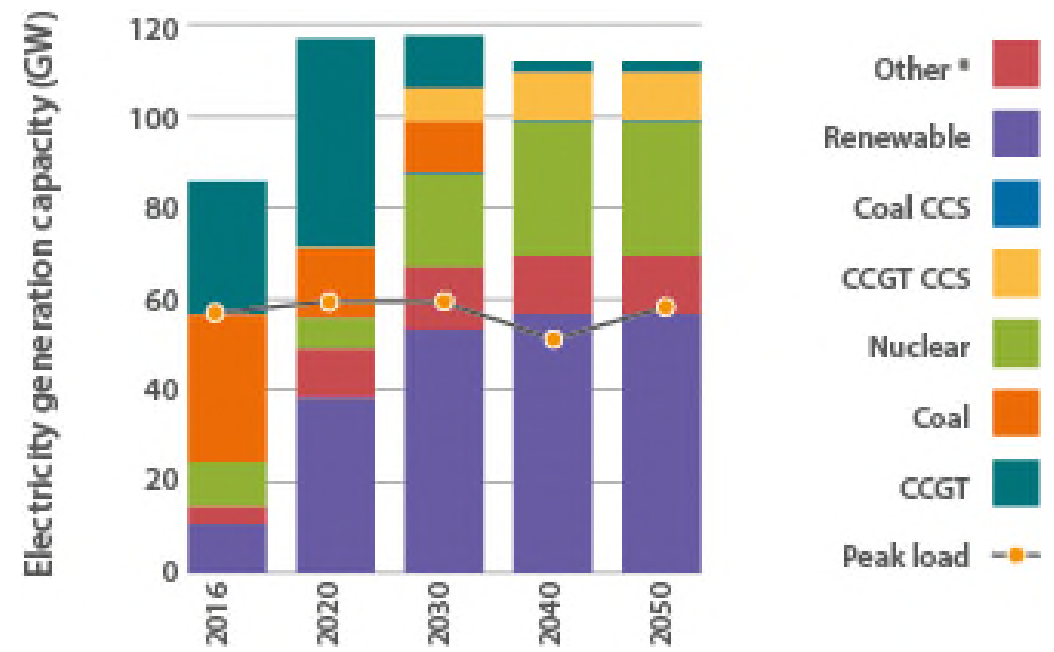

Figure 5 NISMOD analysis of the NNA strategy for electricity generation (central population and economic growth scenario)

The strategy for transport in the NNA recognises that meeting unbounded demand for road transport by provision of additional (free) road space would be infeasibly expensive and release further latent demand. Thus a programme of investments to improve capacity and efficient use of the highway network needs to be accompanied by more active intervention to manage demand. The possibility that car ownership and usage may be peaking ('peak car') and decoupling from economic growth should be encouraged through incentives (road user charging) and technology (Figure 6). The progressive shift from car ownership to purchase of mobility services is expected to render per use charging more acceptable. In-vehicle technologies, notable autonomous vehicles, will enable more efficient use of the road network, though the scale of these efficiency improvements may be limited 
by the capacity of junctions and terminal points (Royal Academy of Engineering, 2015). Driverless vehicles may be particularly beneficial in the freight sector, enabling more efficient use of night-time capacity on the highway network.

Continued investment in capacity in the rail network will be essential (see Figure 6), with the NNA aiming for $15 \%$ of all passenger trips to be by rail. This will require capacity improvements at pinch points in the rail network, continued electrification and rolling stock improvements and extension of High Speed 2 to Glasgow and Edinburgh by 2050.

The NNA has also examined urban transport, recognising the productivity returns to investment in connectivity in London (notably via CrossRail 1 and 2) and the relative deficiency of bus and rail provision in several of the UK's major cities, i.e. Birmingham, Manchester, Leeds, Nottingham, Bristol and Belfast.

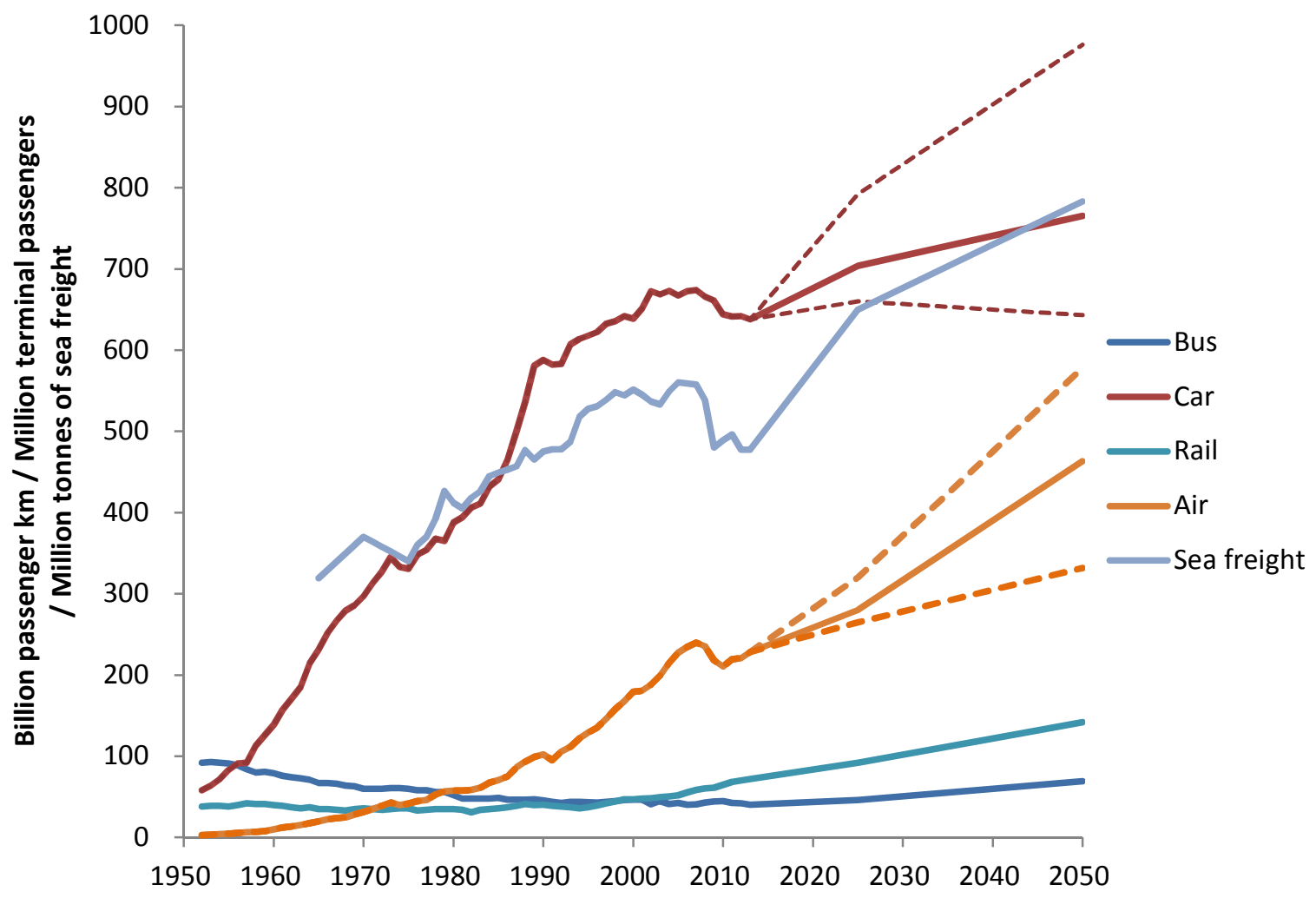

Figure 6 Projections of transport usage for NNA transport strategy and central population/economic scenario. Car and air projections are based on DfT forecasts (Department for Transport, 2015, Department for Transport, 2013), but with more aggressive demand management associated with the lower bound projections for cars

Digital communications system, including fixed and mobile networks, switching stations and data centres, are providing very rapidly increasing capacity, which is a necessary requirement for the digital economy. However, the degree of rapid technological innovation taking place in the sector undermines investment, where operators are cautious to take on risk due to worries over stranded assets. Market failures occur in remote areas where infrastructure provision is unviable based on projected revenues (Figure 7). In these areas regulatory intervention and state support is likely to be necessary. Over the long-term, mobile, fixed wireless and satellite will need to play an increasingly important role in places with low population densities. The Universal Service Obligation (USO) that was announced in $\mathbf{2 0 1 5}$ gives people everywhere in the UK the legal right to request a connection to 
broadband with speeds of $10 \mathrm{Mbps}$, which will meet needs for web browsing and email. More bandwidth will be required to cope with growing demand for video streaming, which already represents $60 \%$ of digital service provision.

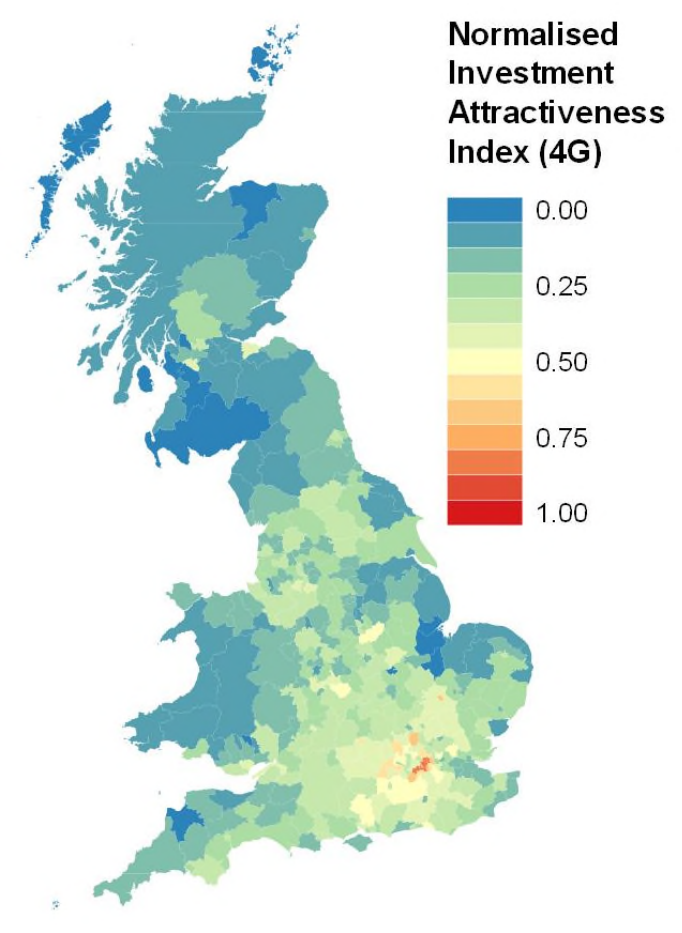

Figure 7 Attractiveness of investment in $4 \mathrm{G}$ mobile communications infrastructure, based on population density, socioeconomic status and ground elevation

Like other infrastructure systems, water supply systems face challenges of increasing population, which will provide upward pressure on demand for public water supplies. Water supplies are particularly vulnerable to the uncertain effects of climate change. There are relatively low cost steps that can be taken to reduce per capital demand to a certain extent. Further reductions in demand and leakage will be more costly but will be necessary alongside strategic investments in water infrastructure. The NNA envisages leakage being reduced to less than $20 \%$ of water supplied, compared to $22 \%$ at present. 


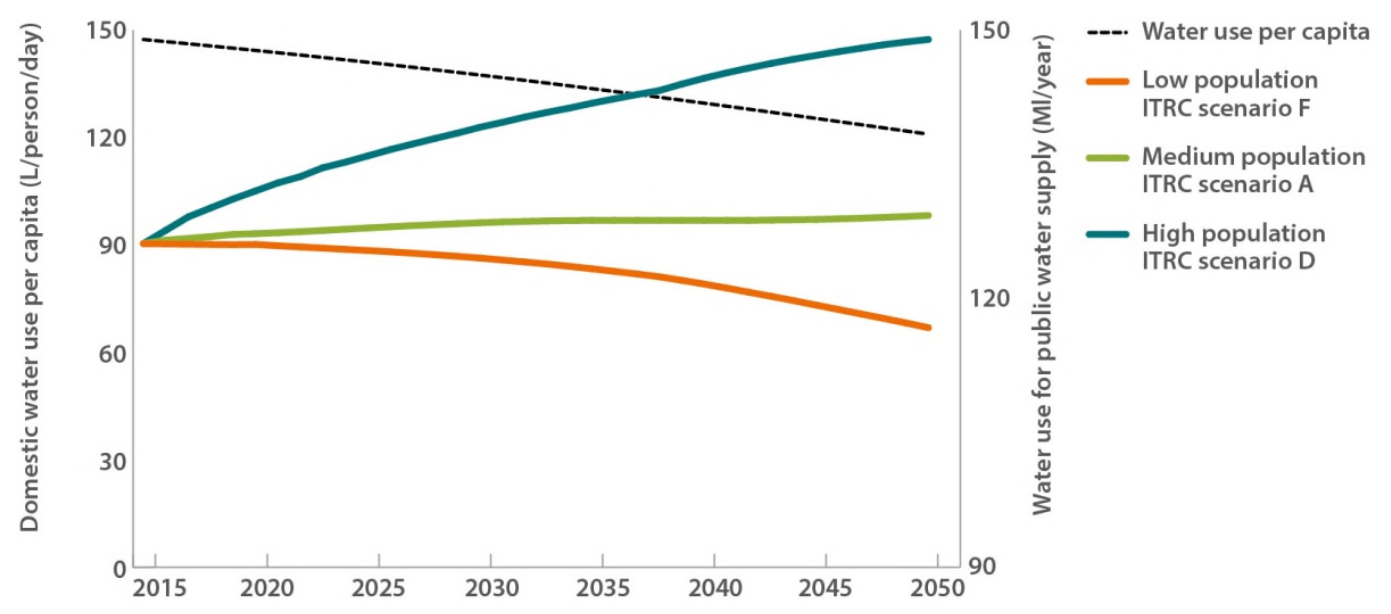

Figure 8 NNA strategy for water demand management and implications for water demand at a national scale

Figure 9 illustrates the projected water supply-demand balance, given the NNA strategy for reductions in per capita water demand and leakage. The NNA recommends increasing strategic transfers of water to address these deficits (which will typically have to be accompanied by storage reservoirs) along with exploitation of groundwater recharge schemes, effluent water reuse and desalination all help to build resilience in the water supply system.
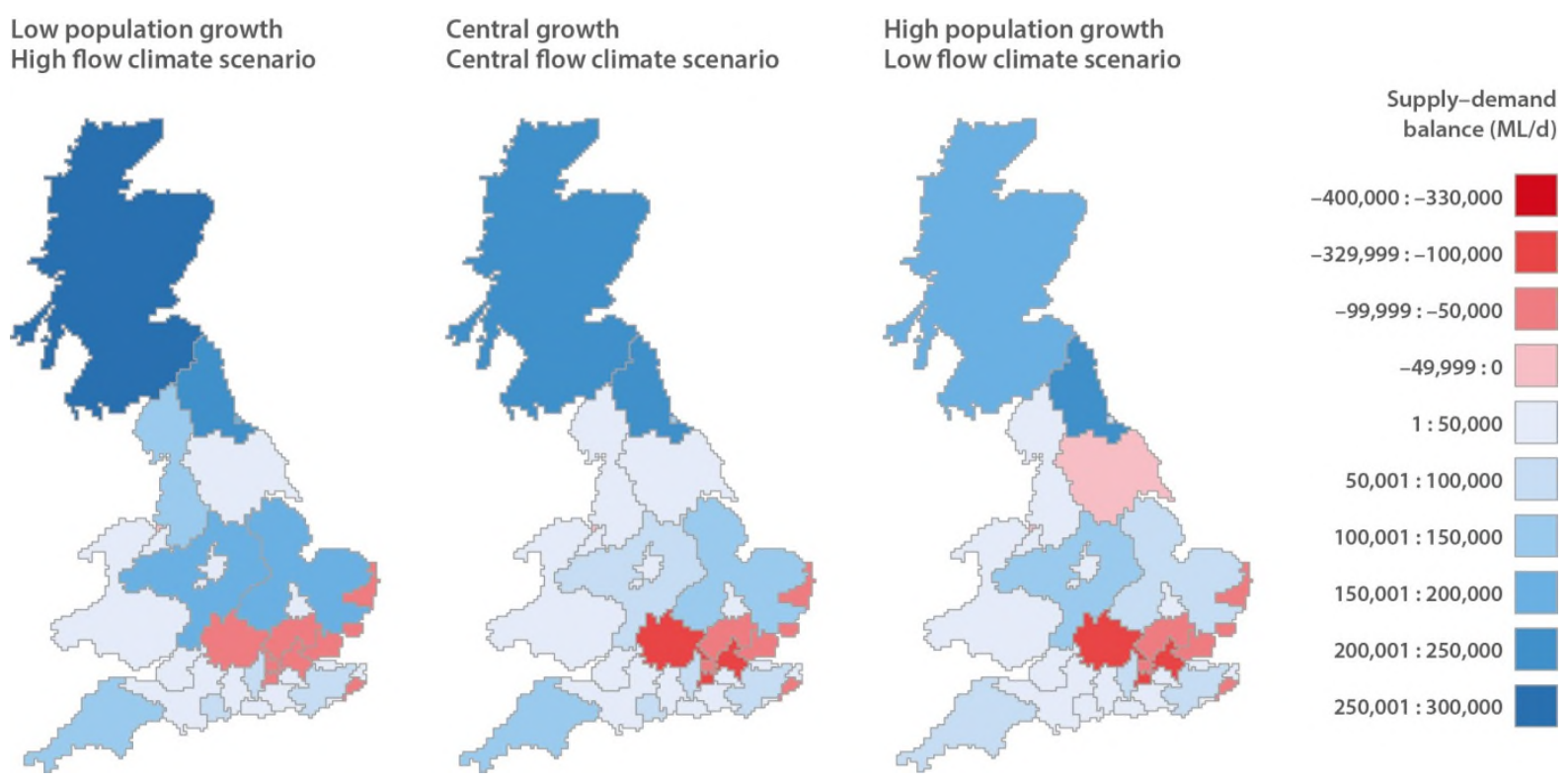

Figure 9 Projections of supply-demand balance for NNA demand management and leakage reduction strategy

Waste water treatment systems have seen a wave of investment to improve effluent standards. There has been an ongoing process of centralisation of treatment facilities into larger more efficient plants, which will continue in future in all but the most isolated settlements. More could be achieved in reducing demands placed upon sewer networks by decreasing water use in buildings and reducing storm water discharges into sewers (for example, by installing sustainable drainage systems and separating storm water from sewage). Nonetheless, additional major investments in waste water infrastructure systems will be required to renew plant, deal with an increasing population, meet improving standards of wastewater discharges and deal with surface water flooding. 
Flood defence infrastructure will need to be extended and upgraded to deal with sea level rise on the coast and the uncertain effects of climate change on river flows. The Environment Agency's Long Term Investment Strategy (Environment Agency, 2014) is based upon cost-benefit analysis of investment in flood defences in 3000 separate flood systems in England, producing an estimate of an optimal investment sequence costing around $£ 860$ million per year, which will see higher standards of protection in urban areas, along with decommissioning of defences in some locations to restore natural catchment and coastal processes. These infrastructure investments should be seen as part of a wider package of flood risk management measures to cease inappropriate development in floodplains and build resilience to flood events that exceed the standard for flood protection.

The NNA foresees the circular economy of solid waste recovery and recycling into valuable resources. Additional action is required to ensure recycling of waste streams, so that household recycling meets the EU target of 50\% by 2020 (up from 44.9\% in 2014). Increased resource recovery means that there will be some diminution of energy generation from waste at incineration plants, with an increasing proportion of waste being recycled. Meanwhile biological waste will provide a contribution to gas supplies. A potentially synergistic innovation is in mixing solid biological waste with sewage sludge, to increase the efficiency of anaerobic digestion. If waste production can be decoupled from economic growth (there is some evidence that this is already taking place (WRAP, 2012)) then there is already sufficient capacity in waste processing infrastructure and the only infrastructure requirement will be in plant renewal.

\section{Conclusions}

Analysis with NISMOD for the NNA has demonstrated the scale of demand for infrastructure services in future. Population and economic growth provide strong upward drivers of demand. There are some signs that demand for infrastructure services (e.g. energy, mobility, solid waste) may be decoupling from growth - but policies to manage demand will have to be more effective than at present for overall demand to remain level or go down. Thus investment in new capacity is required, in particular in the southeast of Britain where growth is strongest. The NNA also emphasises the contribution that new infrastructure can make to unlocking growth elsewhere in the UK, by providing improved transport and digital connectivity which enhances trade, improves access to labour markets and encourages innovation.

Meanwhile, reliable energy, water, waste water, solid waste and flood protection services are essential to the smooth running of the economy and a sustainable environment. The ICE has long recognised the importance of improving the resilience of infrastructure to shocks, be they from natural hazards or man-made threats (ICE, 2009). The NISMOD-RV (Risk and Vulnerability) model, which has not been described here, analyses the risks of infrastructure failure, so can help make the case for investment in resilience (Thacker et al., in press).

The NISMOD national infrastructure systems model provides the capacity to rapidly analyse alternatives and compare them based on a consistent set of metrics. We foresee this process of national infrastructure assessment become progressively more open and inclusive, so that different stakeholders can propose and analyse alternative infrastructure strategies. A shared modelling capability is particularly important in the context of devolution, in which the nations of the UK, regions and cities are taking responsibility for infrastructure. A shared systems view of the UK's 
infrastructure networks will enable separate initiatives to be formulated in the context of a consistent overall strategy.

Finally, whilst NISMOD has been developed for the UK, the ITRC's new Programme Grant from EPSRC will be exploring the transferability of NISMOD to other countries, including: emerging economies where the pace of infrastructure development is fastest; least developed countries where the infrastructure deficit is greatest; post-disaster situations where there is a growing recognition of the need to 'build back better'; and post-conflict situations where infrastructure planning and investment can provide a route to a peaceful and prosperous future. Many aspects of NISMOD need to be adapted to deal with the challenges of these different settings, making the most of new Earth observation datasets and global databases. The challenges are formidable, but we hope that the lessons from infrastructure systems analysis that have been learnt over the last five years in the UK can be of value elsewhere in the world.

\section{Acknowledgements}

We acknowledge the contributions of all the ITRC who have contributed to the development of NISMOD. The ITRC is funded by the Engineering and Physical Sciences Research Council under two Programme Grants. We are grateful to the support of the NNA Executive Group and secretariat.

\section{References}

BYERS, E., HALL, J. W. \& AMEZAGA, J. 2014. Electricity generation and cooling water use: UK pathways to 2050 Global Environmental Change, in review.

DEPARTMENT FOR TRANSPORT 2013. UK Aviation Forescasts.

DEPARTMENT FOR TRANSPORT 2015. Road Traffice Forecasts 2015.

ENVIRONMENT AGENCY 2014. Flood and coastal erosion risk management: Long-term investment scenarios (LTIS) 2014. Bristol: Environment Agency.

FRONTIER ECONOMICS 2015. Energy efficiency: An infrastructure priority.

HALL, J. W., TRAN, M., HICKFORD, A. J. \& NICHOLLS, R. J. 2016. The Future of National Infrastructure: A System of Systems Approach, Cambridge University Press.

HOUSE OF COMMONS 2015. Infrastructure Policy. Briefing Paper 06594.

ICE 2009. The State of the Nation: Defending Critical Infrastructure. London: Institution of Civil Engineers.

MCKAY, D. J. C. 2008. Sustainable Energy - Without the Hot Air, UIT.

OTTO, A., HALL, J. W., HICKFORD, A. J., NICHOLLS, R. J., ALDERSON, D., BARR, S. \& TRAN, M. 2014. A Quantified System-of-Systems Modeling Framework for Robust National Infrastructure Planning. IEEE Systems Journal, 99, 1-12.

ROYAL ACADEMY OF ENGINEERING 2015. The transport congestion challenge getting the most out of the UK's road and rail networks.

THACKER, S., KELLY, S., PANT, R. \& HALL, J. W. in press. Evaluating the benefits of adaptation of critical infrastructures to hydrometeorological risks. Risk Analysis.

VENABLES, A., LAIRD, J. \& OVERMAN, H. 2014. Transport investment and economic performance: Implications for project appraisal. Department for Transport.

WRAP 2012. Decoupling of Waste and Economic Indicators. 